\title{
Thyroid function: a new road to understanding age-related macular degeneration?
}

\author{
Till Ittermann ${ }^{*}$ and Clemens Jürgens
}

\begin{abstract}
Age-related macular degeneration (AMD) continues to be amongst the leading causes of blindness and visual impairment worldwide. AMD remains a degenerative disorder of unknown etiology with rising prevalence. It induces retinal changes and damages those parts of the retina which are essential for central vision. The risk of developing this condition is associated with increasing age. Early stages usually progress without warning signs over years. The major identified risk factors for AMD development are age, ethnicity, family history, and current smoking. Associations of other modifiable risk factors with AMD have been widely published but these studies have reported conflicting results and showed a lack of consistency. According to recent data published in BMC Medicine from the population-based Rotterdam study, thyroid hormones may contribute to a better characterization of AMD in clinical practice. In that study serum free thyroxine levels were positively associated with development of AMD. More studies are needed to validate these findings and to understand better the role of thyroid hormones in the pathogenesis of AMD disease.

Please see related article: http://dx.doi.org/10.1186/s12916-015-0329-0
\end{abstract}

Keywords: Thyroid hormone, Thyroid function, AMD, Age-related macular degeneration

\section{Introduction}

In 1990 and 2010, age-related macular degeneration (AMD) was amongst the leading causes of blindness and visual impairment worldwide [1]. The greatest prevalence was reported in developed countries, especially in high-income regions. Such regions face the strongest demographic shift where overaging societies increase the prevalence of age related diseases in general. In the United States the number of persons affected by AMD was estimated to increase by $50 \%$ until 2020 , based on population demographics [2]. The visual impairment caused by AMD presents a tremendous economic burden and major limitations in quality of life $[3,4]$.

\section{Pathophysiology and clinical aspects of AMD}

AMD increases strongly with age and is characterized by the presence of drusen or pseudodrusen, abnormalities in retinal pigmentation, geographic atrophy, neovascularization, or angiomatous proliferation. Drusen are small white or yellowish extracellular deposits in the

\footnotetext{
*Correspondence: till.ittermann@uni-greifswald.de

Institute for Community Medicine, University Medicine Greifswald, Walther Rathenau Str. 48, D-17475 Greifswald, Germany
}

retina. They are located between the retinal pigment epithelium (RPE) and the Bruch's membrane. A number of grading schemes has been developed based on the size and number of drusen and the amount of other retinal lesions. A common classification was defined by the Age-Related Eye Disease Study (AREDS) [5], which subdivides AMD into the categories no AMD, early AMD, intermediate AMD, and advanced AMD. These stages represent the natural history of $A M D$, which generally progresses from the 'dry' (atrophic) to the 'wet' (neovascular) form. It is clinically important that early stages may persist over many years without any signs or discomfort. The typical AMD patient is over 55 years old and often presents with neovascular conditions as the first manifestation. This can be explained by the fact that pathogenic mechanisms of AMD development and progression remain poorly understood. For this reason, there is no causative therapy available. Instead, the rationale for treatment is to prevent vision loss by delaying onset or progression to later stages, and by reducing neovascularization [6]. Treatment modalities have to be adapted to their respective stages, whereas no benefit of therapeutic interventions has been published for early AMD. 
The conversion from intermediate to advanced AMD might be attenuated by a daily antioxidant therapy. In 2001 the AREDS group reported a reduced odds ratio of 0.72 in the antioxidants group [5]. The introduction of substances that inhibit vascular endothelial growth factors (VEGF) led to more effective treatments of neovascularization. Consequently, intravitreal injection of anti-VEGF drugs has become primary therapy for most cases of advanced AMD [7]. The repeated application of these substances obtains beneficial therapeutic effects in the macular region resulting in good visual restoration. Potential systemic side effects of these agents aroused concerns about cardiovascular and hematologic complications, but the real evidence of such events is largely unknown.

\section{Screening and diagnostic procedures}

Several diagnostic tests have been established to assess signs of AMD. Funduscopy, optical coherence tomography, and angiography are medical imaging procedures used to diagnose AMD and to determine disease progression. Testing visual acuity is essential to evaluate visual impairment. Early treatment is crucial for patients who develop wet AMD, because it reduces the risk of vision loss and may improve the final visual outcome. With the introduction of new therapeutic methods, early detection will also become increasingly important for early AMD stages. However, screening for AMD is not common yet. Although patients' self-testings (that is, Amsler grid [8]) show low sensitivity [9], best practice guidelines recommend encouraging patients to assess their own visual acuity [6]. Improved knowledge of risk factors may help to develop comprehensive screening strategies.

\section{Risk factors}

Several studies have identified age, ethnicity, and family history (genetics) as major risk factors for the development of wet AMD [10,11]. Smoking is also strongly associated with AMD. It appears to be the only modifiable risk factor that has been consistently identified in the literature [12]. Smoking cessation reduces the risk of AMD development and progression. Thus, it should be beneficial to generate awareness about the risk of developing AMD from the toxic effects of cigarette smoking. Associations with other modifiable risk factors have been widely published but these studies have reported conflicting results and showed a lack of consistency: hypertension and cardiovascular risk factors [13-20], dietary fat intake [11,20-25], aspirin use [26,27], sunlight exposure [28-30], and alcohol [31]. Thus, the pathogenesis of AMD is currently poorly understood and it is important to identify potential risk factors for this disease. The work by Chaker et al. suggests that thyroid function is an important risk factor for AMD [32]. In that study, based on data from the population-based Rotterdam study, serum free thyroxine levels were positively associated with development of AMD. There was no association of serum thyroid-stimulating hormone (TSH) with this outcome.

\section{Association between serum TSH levels and macular degeneration within the Study of Health in Pomerania (SHIP-Trend)}

In SHIP-Trend, a population-based cross-sectional study conducted in Northeast Germany, data from 3,070 individuals 20 - to 80 -years old were available to investigate the association between serum TSH levels and macular degeneration [33]. Serum TSH levels were measured by an immunochemiluminescent procedure (Vista, Siemens, Eschborn, Germany). Macular degeneration was evaluated by an experienced reader based on images from fundus photography of the central retina derived from a non-mydriatic fundus camera (TRC-NW 200, Topcon Corporation, Tokyo, Japan) [34]. There were 62 individuals with macular degeneration in SHIP-Trend (2.0\%). In logistic regression adjusted for age, sex, smoking status, hypertension, cholesterol, diabetes and body mass index we found, in agreement with the findings of Chaker et al., no significant association between serum TSH levels and macular degeneration (odds ratio $(\mathrm{OR})=0.99 ; 95 \%$ confidence interval $(\mathrm{CI})=0.92$ to 1.07 ). Likewise, there was no significant association between serum TSH levels within the reference range and macular degeneration $(\mathrm{OR}=1.08$; $95 \% \mathrm{CI}$ : 0.63 to 1.84$)$. Restricting the age range to individuals $\geq 55$ years did not change the results significantly. Unfortunately, serum fT4 levels were not measured in SHIP-Trend, so that we were not able to verify the significant positive association between fT4 and macular degeneration detected in the Rotterdam study.

\section{Conclusions}

AMD is a disease whose risk factors and pathophysiology are not well understood and, thus, AMD is often diagnosed in an already advanced stage. Thyroid hormones may contribute to a better characterization of AMD in clinical practice as shown by the data of Chaker et al. [32].

Even though observational studies cannot determine causal inference, they provide useful evidence to improve the perception of specific illnesses. However, more studies are needed to validate the findings of Chaker et al. and to understand better the role of thyroid hormones in the pathogenesis of the AMD disease.

\section{Competing interests}

The authors declare that they have no competing interests. 


\section{Authors' information}

$\mathrm{TI}$ is a statistician by training and has eight years experience as an epidemiologist. He is currently the leader of the statistical methods unit of the Department of SHIP/Clinical-Epidemiological Research at the University Medicine Greifswald and has great expertise in the analysis of observational data. His main research field is thyroid epidemiology. CJ is the Medical Director of the examination centre of the Study of Health in Pomerania (SHIP) at the University Medicine Greifswald, Germany. He studied medicine and obtained his doctorate at the Medical University Hannover, Germany. He completed his medical and scientific training at the Universities of Tübingen, Hannover and Greifswald, Germany. His professional experience includes clinical and scientific research in the areas of experimental ophthalmology, medical imaging, telemedicine, artificial intelligence, and computer science. His main clinical and research interests are retinal diseases, glaucoma, ophthalmic epidemiology, e-health, and visual computing.

\section{Acknowledgements}

The Study of Health in Pomerania is part of the Community Medicine Research Network of the University Medicine Greifswald, which was funded by the German Federal Ministry for Education and Research, the Ministry for Education, Research and Cultural Affairs, and the Ministry for Social Affairs of the State Mecklenburg-West Pomerania. Analyses were further supported by the German Research Foundation (DFG VO955/10-2 and DFG VO955/12-1) and the BMELV.

\section{Received: 7 April 2015 Accepted: 7 April 2015}

\section{Published online: 23 April 2015}

\section{References}

1. Bourne RR, Stevens GA, White RA, Smith JL, Flaxman SR, Price $H$, et al. Causes of vision loss worldwide, 1990-2010: a systematic analysis. Lancet Glob Health. 2013;1:e339-49.

2. Friedman DS, O'Colmain BJ, Muñoz B, Tomany SC, McCarty C, de Jong PT, et al. Prevalence of age-related macular degeneration in the United States. Arch Ophthalmol. 2004;122:564-72.

3. Cruess A, Zlateva G, Xu X, Rochon S. Burden of illness of neovascular agerelated macular degeneration in Canada. Can J Ophthalmol. 2007;42:836-43.

4. Cruess AF, Zlateva G, Xu X, Soubrane G, Pauleikhoff D, Lotery A, et al. Economic burden of bilateral neovascular age-related macular degeneration: multi-country observational study. Pharmacoeconomics. 2008;26:57-73.

5. Age-Related Eye Disease Study Research Group. A randomized, placebocontrolled, clinical trial of high-dose supplementation with vitamins $C$ and E, beta carotene, and zinc for age-related macular degeneration and vision loss: AREDS report no. 8. Arch Ophthalmol. 2001;119:1417-36.

6. American Academy of Ophthalmology Retina/Vitreous Panel. Preferred Practice Pattern ${ }^{\oplus}$ Guidelines. Age-Related Macular Degeneration. San Francisco, CA: American Academy of Ophthalmology; 2015. Available at: www.aao.org/ppp.

7. Solomon SD, Lindsley K, Vedula SS, Krzystolik MG, Hawkins BS. Anti-vascular endothelial growth factor for neovascular age-related macular degeneration. Cochrane Database Syst Rev. 2014;8, CD005139. doi:10.1002/14651858. CD005139.pub3.

8. Amsler M. Earliest symptoms of diseases of the macula. Br J Ophthalmol. 1953;37:521-37.

9. Crossland M, Rubin G. The Amsler chart: absence of evidence is not evidence of absence. Br J Ophthalmol. 2007;91:391-3.

10. Klein R, Peto T, Bird A, Vannewkirk MR. The epidemiology of age-related macular degeneration. Am J Ophthalmol. 2004;137:486-95.

11. Clemons TE, Milton RC, Klein R, Seddon JM, Ferris 3rd FL, Group A-REDSR. Risk factors for the incidence of Advanced Age-Related Macular Degeneration in the Age-Related Eye Disease Study (AREDS) AREDS report no. 19. Ophthalmology. 2005;112:533-9.

12. Thornton J, Edwards R, Mitchell P, Harrison RA, Buchan I, Kelly SP. Smoking and age-related macular degeneration: a review of association. Eye (Lond). 2005;19:935-44.

13. Age-Related Eye Disease Study Research Group. Risk factors associated with age-related macular degeneration. A case-control study in the age-related eye disease study: Age-Related Eye Disease Study Report Number 3. Ophthalmology. 2000;107:2224-32.
14. Delcourt C, Michel F, Colvez A, Lacroux A, Delage M, Vernet MH, et al. Associations of cardiovascular disease and its risk factors with age-related macular degeneration: the POLA study. Ophthalmic Epidemiol. 2001;8:237-49.

15. McCarty CA, Mukesh BN, Fu CL, Mitchell P, Wang JJ, Taylor HR. Risk factors for age-related maculopathy: the Visual Impairment Project. Arch Ophthalmol. 2001;119:1455-62.

16. Hyman L, Schachat AP, He Q, Leske MC. Hypertension, cardiovascular disease, and age-related macular degeneration. Age-Related Macular Degeneration Risk Factors Study Group. Arch Ophthalmol. 2000;118:351-8.

17. Klein R, Deng Y, Klein BE, Hyman L, Seddon J, Frank RN, et al. Cardiovascular disease, its risk factors and treatment, and age-related macular degeneration: Women's Health Initiative Sight Exam ancillary study. Am J Ophthalmol. 2007; 143:473-83.

18. Fernandez AB, Wong TY, Klein R, Collins D, Burke G, Cotch MF, et al. Agerelated macular degeneration and incident cardiovascular disease: the Multi-Ethnic Study of Atherosclerosis. Ophthalmology. 2012;119:765-70.

19. Olea JL, Tuñón J. Patients with neovascular age-related macular degeneration in Spain display a high cardiovascular risk. Eur J Ophthalmol. 2012;22:404-11.

20. Seddon JM, Rosner B, Sperduto RD, Yannuzzi L, Haller JA, Blair NP, et al. Dietary fat and risk for advanced age-related macular degeneration. Arch Ophthalmol. 2001;119:1191-9.

21. Mares-Perlman JA, Brady WE, Klein R, VandenLangenberg GM, Klein BE, Palta M. Dietary fat and age-related maculopathy. Arch Ophthalmol. 1995;113:743-8

22. Smith W, Mitchell P, Leeder SR. Dietary fat and fish intake and age-related maculopathy. Arch Ophthalmol. 2000;118:401-4.

23. Cho E, Hung S, Willett WC, Spiegelman D, Rimm EB, Seddon JM, et al. Prospective study of dietary fat and the risk of age-related macular degeneration. Am J Clin Nutr. 2001;73:209-18.

24. Sangiovanni JP, Agrón E, Meleth AD, Reed GF, Sperduto RD, Clemons TE, et al. \{omega\}-3 Long-chain polyunsaturated fatty acid intake and 12-y incidence of neovascular age-related macular degeneration and central geographic atrophy: AREDS report 30, a prospective cohort study from the Age-Related Eye Disease Study. Am J Clin Nutr. 2009;90:1601-7.

25. Chua B, Flood V, Rochtchina E, Wang JJ, Smith W, Mitchell P. Dietary fatty acids and the 5-year incidence of age-related maculopathy. Arch Ophthalmol. 2006:124:981-6.

26. Klein BE, Howard KP, Gangnon RE, Dreyer JO, Lee KE, Klein R. Long-term use of aspirin and age-related macular degeneration. JAMA. 2012;308:2469-78.

27. Christen WG, Glynn RJ, Ajani UA, Schaumberg DA, Chew EY, Buring JE, et al. Age-related maculopathy in a randomized trial of low-dose aspirin among US physicians. Arch Ophthalmol. 2001;119:1143-9.

28. Delcourt C, Carrière I, Ponton-Sanchez A, Fourrey S, Lacroux A, Papoz L, et al. Light exposure and the risk of age-related macular degeneration: the Pathologies Oculaires Liées à I'Age (POLA) study. Arch Ophthalmol. 2001;119:1463-8.

29. Cruickshanks KJ, Klein R, Klein BE, Nondahl DM. Sunlight and the 5-year incidence of early age-related maculopathy: the beaver dam eye study. Arch Ophthalmol. 2001;119:246-50.

30. Khan JC, Shahid H, Thurlby DA, Bradley M, Clayton DG, Moore AT, et al. Age related macular degeneration and sun exposure, iris colour, and skin sensitivity to sunlight. Br J Ophthalmol. 2006;90:29-32.

31. Chong EW, Kreis AJ, Wong TY, Simpson JA, Guymer RH. Alcohol consumption and the risk of age-related macular degeneration: a systematic review and meta-analysis. Am J Ophthalmol. 2008;145:707-15.

32. Chaker L, Buitendijk GHS, Dehghan A, Medici M, Hofman A, Vingerling JR, et al. Thyroid function and age-related macular degeneration: a prospective population-based cohort study - The Rotterdam Study. BMC Medicine. DOl:10.1186/s12916-015-0329-0.

33. Völzke H, Alte D, Schmidt CO, Radke D, Lorbeer R, Friedrich N, et al. Cohort profile: the study of health in Pomerania. Int J Epidemiol. 2011;40:294-307.

34. Ittermann T, Dorr M, Volzke H, Tost F, Lehmphul I, Kohrle J, et al. High serum thyrotropin levels are associated with retinal arteriolar narrowing in the general population. Thyroid. 2014;24:1473-8. 